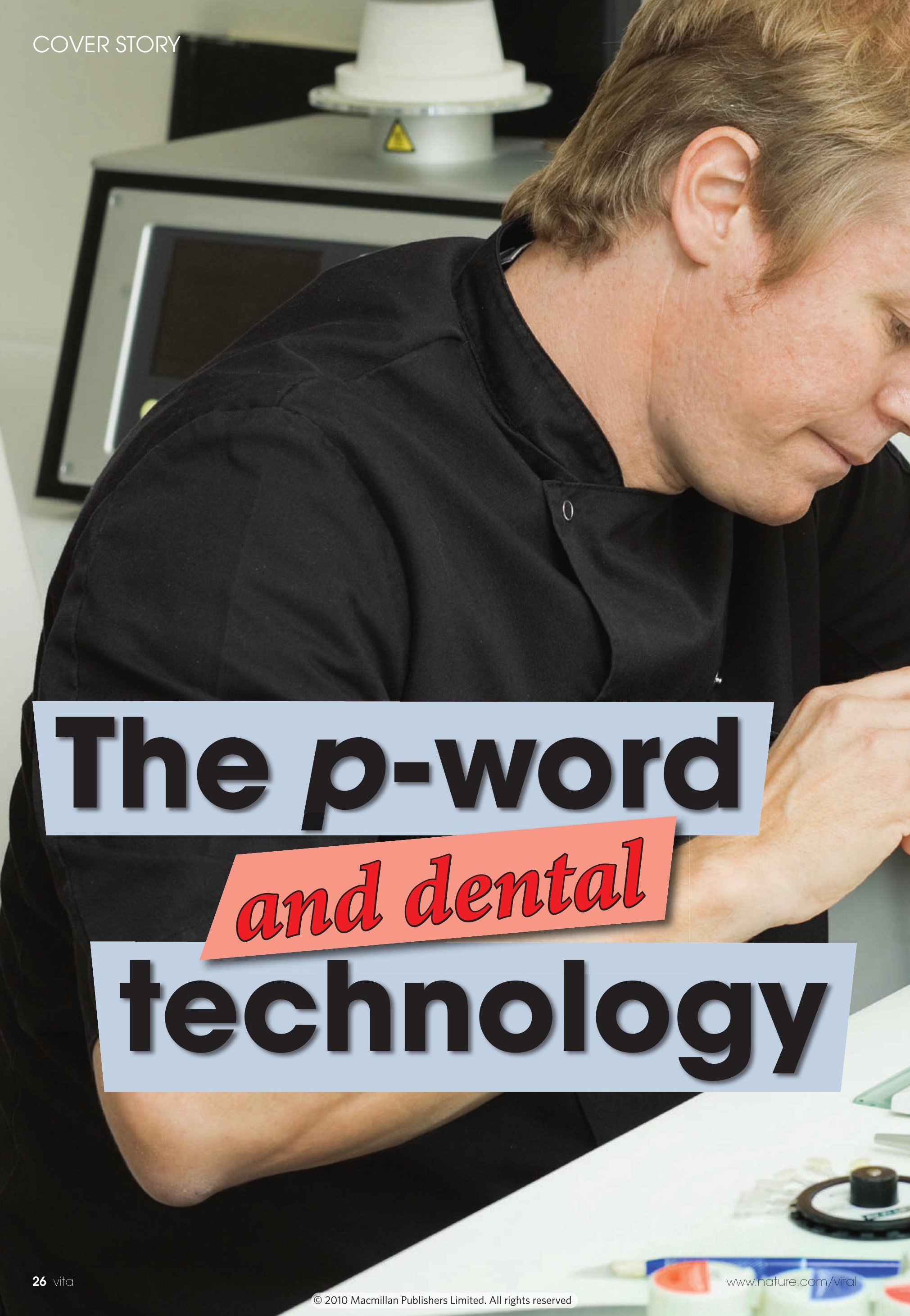


In summer 2004,

\section{Caroline Holland}

wrote in Vital about the working relationship between dentists and dental technicians. ${ }^{1}$ Six years on she heads back to the lab and writes about the transition of the dental technician from artisan to 'professional'.

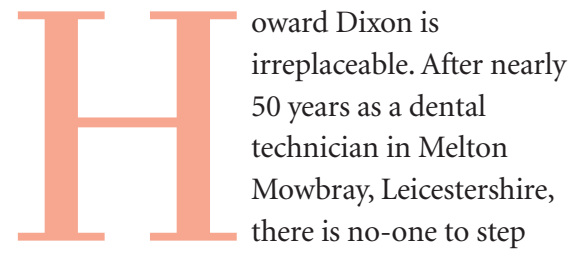

into his shoes when he retires. Self-employed, single-handed technicians cannot survive in the twenty-first century, he says.

He partly blames registration, introduced by the General Dental Council (GDC) for dental technicians on 31 July 2008 (see panel). It has brought an added layer of administration and cost at a time when paperwork and prices are increasing anyway. As a craftsman who works at a bench, carrying out repairs to dentures and with no ambition to do crown and bridge work, he feels that registration is irrelevant to him.

He is not alone. Many dental technicians believe that responsibility for patient care lies with the prescribing dentist. One high profile laboratory owner described registration as 'complete overkill'. Having to carry out continuing professional development (CPD) does not make technicians more skilful, he says, it makes laboratory owners more stressed, since they bear much of the cost.

As an example, he refers to the technician in his lab who carries out the goldwork. Because this employee is highly specialised it would be impossible to find a course or a book which can extend his knowledge or skill in his field. 
Yet he, the lab owner, feels obliged to allow the employee to take time off work to undertake $\mathrm{CPD}$ in areas such as medical emergencies, which is of no use to his business.

This lab owner is surprised that the training to become a technician is now a degree course. 'The GDC is trying to make us something we are not. I am an artisan and I have come far without a degree. Patients trust their dentist to find a laboratory to produce excellent work and that should be enough.'

But this point of view is not shared by the GDC. Alison Lockyer, the GDC chair, said: 'Dental technicians are an important part of the dental team. [...] Even those who will never meet a patient face-to-face have responsibilities towards those who are receiving their work and to other members of the dental team. That's why we expect them to carry out CPD and meet our other regulatory requirements.'

She said that as a result of registration, dental technicians have a clear framework in which to define their professionalism. Professionalism, the ' $\mathrm{p}$ ' word, and how it is applied to dental technicians and the work they do is at the very heart of the issue. The traditional understanding of the word professional is someone who has engaged in specialised educational training, like a dentist.

The job of the technician is to combine artistry with small scale manufacturing. Unlike other dental team members, their role is not clinical, nor is it academic and so they are not professionals as the word is commonly understood. The title of dental care professional (DCP) is a bewildering development although those I spoke to are more than happy to describe their service as professional.
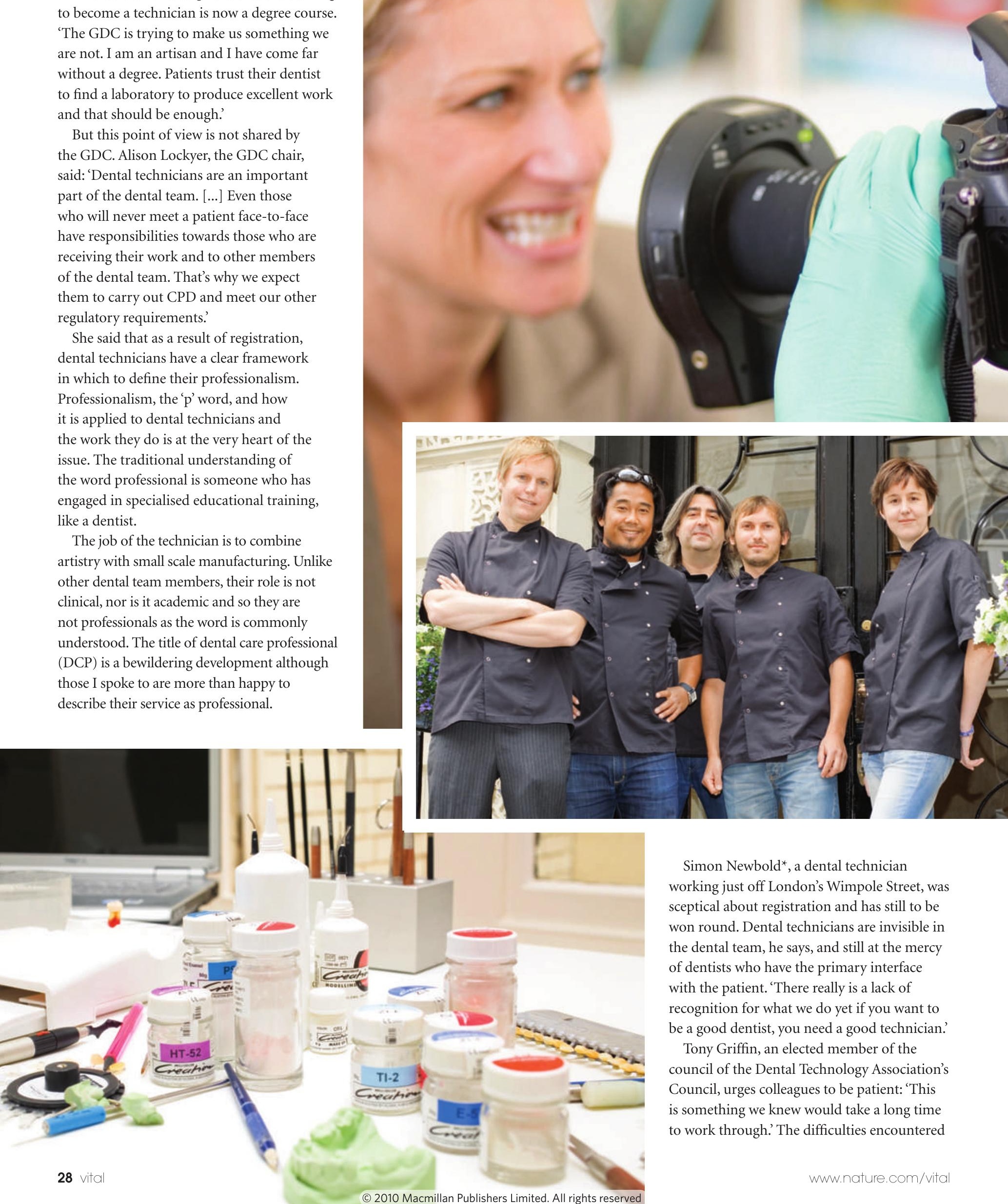

Simon Newbold ${ }^{\star}$, a dental technician working just off London's Wimpole Street, was sceptical about registration and has still to be won round. Dental technicians are invisible in the dental team, he says, and still at the mercy of dentists who have the primary interface with the patient. 'There really is a lack of recognition for what we do yet if you want to be a good dentist, you need a good technician.'

Tony Griffin, an elected member of the council of the Dental Technology Association's Council, urges colleagues to be patient: 'This is something we knew would take a long time to work through.' The difficulties encountered 
'There really is a lack of recognition for

\section{what we do yet if you}

want to be a good

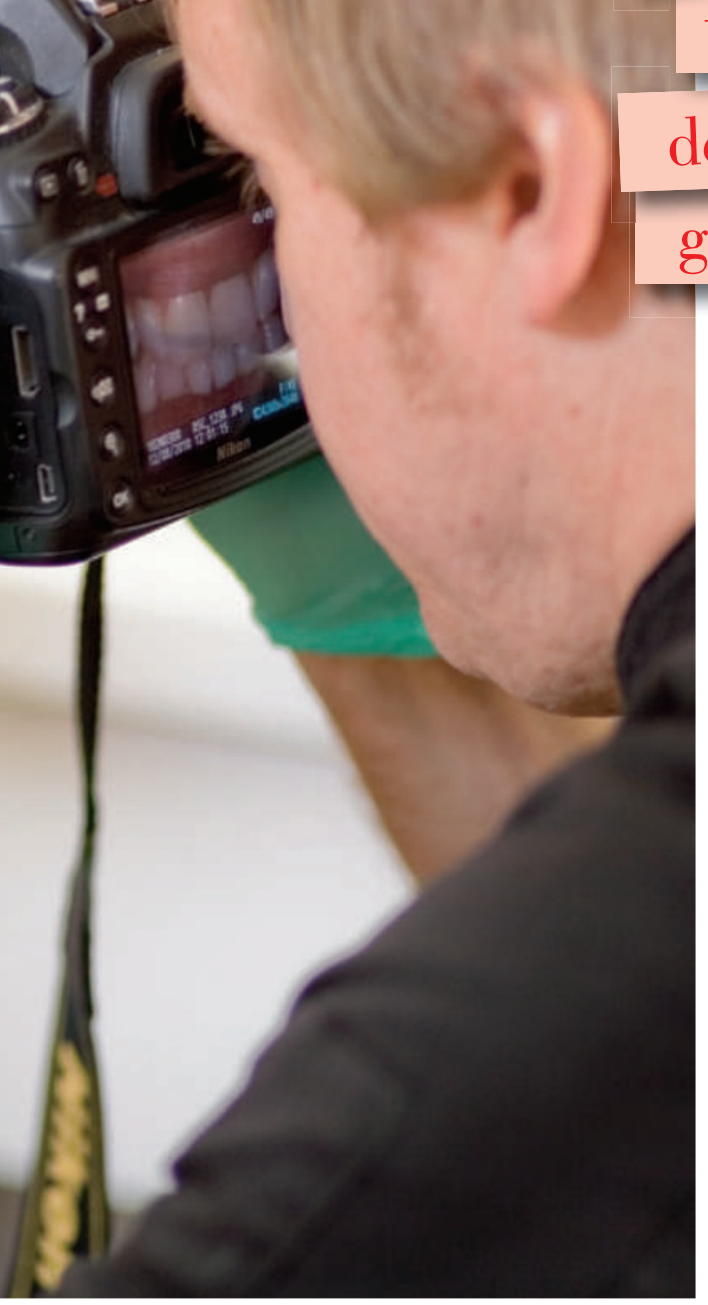

so far are inevitable, he believes, as dental technicians are expected to review and change their work as well as, in some cases, the way they live their lives. 'I can understand what some employers are going through right now and it must be quite difficult.'

He believes dental technicians need to stay on top of new technologies such as CAD/CAM which can revolutionise the way they work and that the requirement for CPD supports and encourages such learning.

Meanwhile, new technologies make some dental technicians fear for the future. They are uncertain about the kind of work the next generation of dental technicians will be doing. Just in the last decade, the profile of the industry has changed dramatically. According to some reckonings, there were an estimated 12,000 dental technicians working in the
UK but now there are just over 7,000 on the register, of whom more than 2,500 trained overseas.

Registration will have had an impact, undoubtedly, with some opting not to register but work illegally instead. Another factor is the growing trend for laboratory work to be sent overseas at prices which undercut British laboratories. The combined effect of falling prices, overseas competition and registration may have persuaded some dental technicians to give up altogether.

Dental technicians working for dentists in the NHS have suffered most in recent years. This has a lot to do with the dental contract introduced in 2006 (see panel) which caused the amount of work commissioned by dentists to plummet. More recently there has been the recession which led to sterling falling against other currencies and pushing the cost of materials up. NHS dentistry had the full support of the Government, which was putting extra money in, but it has been bad for the financial health of UK dental laboratories.

Andrew Taylor is a lab owner in Dronfield in the Midlands and his income reduced by about $30 \%$ following the introduction of the contract. One of the flaws of the contract, he says, is the way the payment system, Units of Dental Activity (UDA) were devised. He says the rate of Band 3 UDAs were calculated to take account of the laboratory element. Because Primary Care Trusts are unable

\section{Registration}

The principal aim of healthcare regulation is to protect patients and this is achieved in dentistry through registration with the General Dental Council (GDC). Registration for dental nurses, dental technicians, clinical dental technicians and orthodontic therapists was introduced on 1 August 2008. The right to work is conferred by registration but can be withdrawn if registrants do not comply with the GDC's Standards for dental professionals. This sets out the principles all dental professionals should follow. DCPs must also engage in continuing professional development (CPD) requirements as laid out on the website - www.gdc-uk.org.

By law DCPs must complete 150 hours of CPD over every five-year cycle. Failure to meet $C P D$ requirements can result in removal from the GDC's register.

There is one difference for technicians.

For all other groups the three core subjects are:

- Medical emergencies (at least ten hours in every CPD cycle)

- Disinfection and decontamination (at least five hours in every CPD cycle)

- Radiography and radiation protection (at least five hours in every CPD cycle).

Dental technicians can substitute radiography and radiation protection with materials and equipment, as the application of radiography is not covered in the curriculum for dental technicians.

The GDC recommends that dental technicians do CPD in medical emergencies every year. If they work in a clinical environment, the GDC also recommends they keep up-to-date by doing CPD in legal and ethical issues, and handling complaints.

All registrants must also be indemnified in case of mishap leading to a patient making a claim.

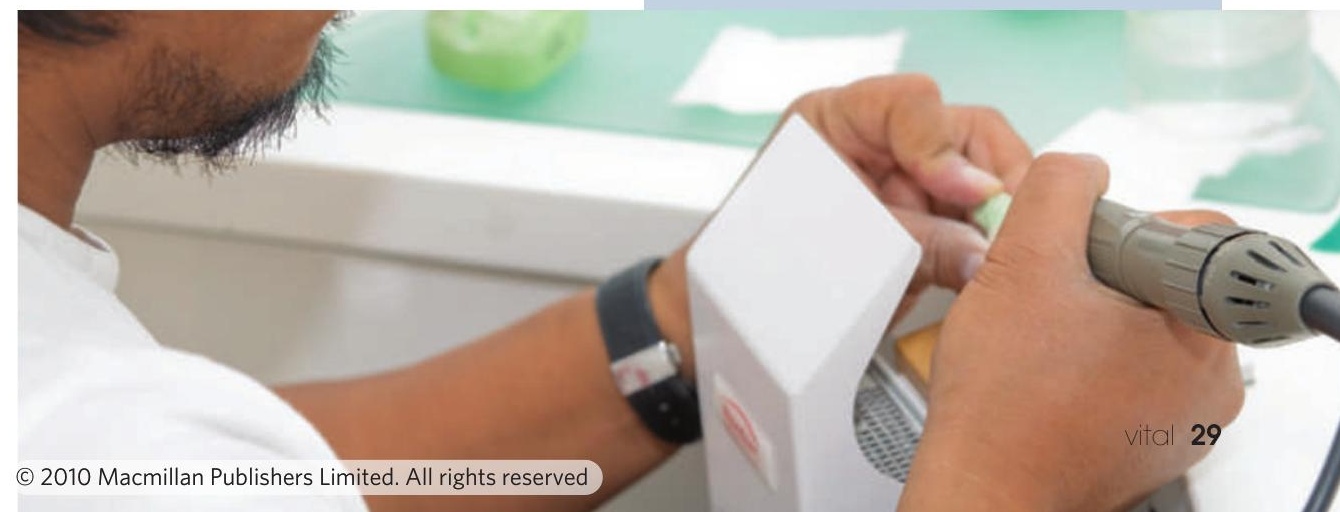


'If you have a quality

product, you are

more likely to survive,

which is why I think

it is important for

\section{technicians to better}

\section{themselves and having to}

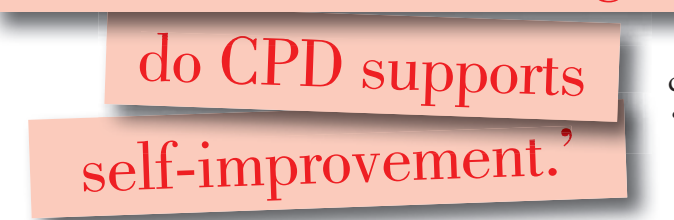

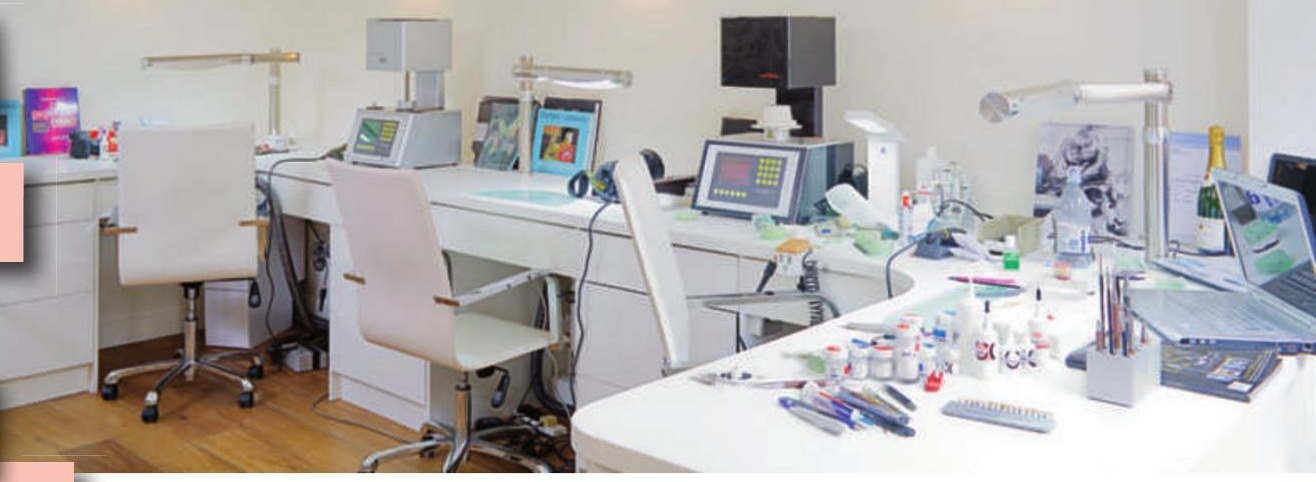

to monitor how many Band 3 UDAs have been carried out, there is no objective way of measuring the change in prescribing patterns. He only has to look at his bottom line, however, to know that that dentists are providing fewer treatments of this kind.

Despite the above, he says he was one of the lucky ones. He only had to make one staff member redundant as another left of their own accord making it possible for his lab, Pacor Dental Ceramics, to stay in business. Through his teaching role with the local Postgraduate Deanery he has been able to organise courses which are cost-effective - the last one being on disinfection and costing delegates just $£ 20$. He appreciates the value of $\mathrm{CPD}$ and the opportunities to network with others in the same business and believes it probably is the way forward.

What he doesn't like is the way it was introduced. If the GDC had carried out an impact assessment, he argues, then registration might have been introduced differently. The GDC argues that it consulted widely. Alison Lockyer elaborates: 'Included in that consultation were more than 500 interested organisations and focus groups were held to ensure their views were heard.' Andrew Taylor says that dental technicians were not contacted directly and many were unaware of the GDC's consultation. Furthermore, consultation is very different from an impact assessment, which is recommended by the Better Regulation Executive 'if appropriate'. Andrew argues that an impact assessment would have been highly appropriate given the impact that registration has had on the world of dental technology.

The GDC says it routinely examines its policies and their impact. Alison Lockyer again: 'We review our policies on an ongoing basis and the registration and CPD requirements for technicians are no different. However, as both are still relatively new it is probably too soon to begin a review; that is more likely to happen within the next five years.'

Generally, technicians working in restorative dentistry are more likely to be in favour of registration. Richard Gidden, of Oral Design, based in the West End of London, works for a

\section{The dental contract of 2006}

The aim of the new dental funding system introduced in April 2006 was to cap spending on dentistry. Primary Care Trusts (PCTs) took over responsibility for managing NHS dental services in their area as part of their overall health budget. A further aim was to get rid of the 'fee per item' system and replace a treatment-based approach with a preventive one. Now, payment is based around courses of treatment which fall into one of three bands, Band 1 being the most simple and Band 3 the most complex. Dentists are paid a set number of Units of Dental Activity (UDAs) depending on the band. A course of treatment that includes some laboratory work falls into Band 3 which attracts 12 UDAs. Professor Jimmy Steele was appointed to carry out a review following widespread criticism of the contract and his recommendations for improving it have been incorporated into a 'blended contract' now being trialled in pilot sites.

small number of private dentists around the country. Some $70 \%$ of his income is derived from implant work.

Registration has not made any immediate difference to him personally but it has drawn a line, he says. In future anyone wanting to enter the profession - and in his view it is a profession - will have to be appropriately qualified. Registration is one way of distinguishing those who are committed to high standards in dental technology.

Setting high standards is also good business, he maintains: 'If you have a quality product, you are more likely to survive, which is why I think it is important for technicians to better themselves and having to do CPD supports selfimprovement.' This is very much the view of the GDC which argues that CPD is in the best interests of patients - and that completing CPD will help registrants develop their own careers.

But he is aware that he speaks from a privileged position which is not having to compete to provide work to dentists in the NHS. The lower end of the market is already too price competitive, he believes, and we can expect to see more dental labs struggling to survive.

Howard Dixon, the dental technician in Melton Mowbray, knows that his small laboratory has no chance of survival after he retires. This is bad news for the dentists who send him work and the patients who value his prompt turnaround. Progress always seems to carry a price and in this case it will be the decline of small local laboratories which have served their community for generations.

\section{Holland C. Profitable partnerships. Vital summer 2004; 22-24.}

${ }^{\star}$ Simon Newbold, who appears on the cover of this issue, also appeared on the cover of the summer 2004 issue of Vital.

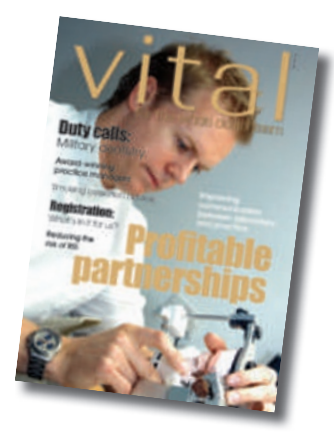

